\title{
Moraxella bovis: influência das características genotípicas e fenotípicas no controle da Ceratoconjuntivite Infecciosa Bovina
}

\author{
Moraxella bovis: influence of genotypic and phenotypic characteristics on \\ Infectious Bovine Keratoconjunctivitis control
}

\author{
Fabricio Rochedo Conceição ${ }^{1}$ Carlos Gil Turnes $^{2}$
}

\section{RESUMO}

A Ceratoconjuntivite Infecciosa Bovina (CIB) continua sendo a mais importante enfermidade ocular dos bovinos da região do MERCOSUL. O agente etiológico da CIB, a bactéria Moraxella bovis, apresenta diferenças genéticas que determinam variações antigênicas e de susceptibilidade aos fármacos, que dificultam seu controle. São discutidos, neste trabalho, resultados de estudos moleculares, antigênicos e de susceptibilidade a antimicrobianos realizados com cepas isoladas durante os últimos vinte anos na região e comparados com os de outras regiões.

Palavras-chave: $C I B$, Moraxella bovis, diversidade antigênica, perfis moleculares.

\section{ABSTRACT}

Infectious Bovine Keratoconjunctivitis (IBK) is still the most important ocular disease of cattle in the MERCOSUL region. The etiologic agent of IBK, the bacterium Moraxella bovis, has genetic differences responsible for antigenic and antibiotic susceptibility variability that interfere in its control. In this review, molecular, antigenic and antimicrobial susceptibility studies of strains recovered during the last 20 years in our region are discussed and compared with results obtained abroad.

Key words: IBK, Moraxella bovis, antigenic diversity, molecular profiles.

\section{INTRODUÇÃO}

A Ceratoconjuntivite Infecciosa Bovina (CIB), também conhecida por "pinkeye", lágrima e olho branco, a doença ocular mais importante dos bovinos
(WILCOX, 1970, BAPTISTA, 1979), pode apresentar curso agudo, subagudo ou crônico, afetando apenas um ou ambos olhos (PUNCH et al., 1985). Seus primeiros sinais são lacrimejamento intenso, fotofobia e blefaroespasmo, seguidos, um a dois dias após, de opacidade no centro da córnea, que pode evoluir até ulceração, ocasionando cegueira temporária ou permanente, descematocele e ruptura da córnea (GIL TURNES, 1998). O agente etiológico da CIB, Moraxella bovis (WILCOX, 1970, CHANDLER et al., 1979), é o único microorganismo capaz de reproduzir a doença de acordo com os postulados de Koch (KODJO et al., 1994).

A CIB não é uma doença fatal, porém seu impacto econômico é enorme, decorrente da perda da visão, a qual é responsável pela perda de peso, redução na produção de leite, dificuldades de manejo e custo de tratamentos (SLATTER et al., 1982, TROUT \& SCHURIG, 1985, SHRYOCK et al., 1998, MARRION \& RILEY, 2000), estimando-se em U\$ 13 por terneiro afetado (TROUT \& SCHURIG, 1985). Na Austrália, estimou-se que a doença produziu perdas superiores a 22 milhões de dólares em 1979 (SLATTER et al., 1982), e nos Estados Unidos, em 1993, de 150 milhões de dólares (KIRKPATRICK \& LALMAR, 1997). Em um estudo realizado em 1997, pelo Departamento de Agricultura dos Estados Unidos da América (USDAUSA), a CIB foi a doença que apresentou a maior prevalência em fêmeas em reprodução e a segunda em bovinos desmamados (KIRKPATRICK \& LALMAR, 1997). O impacto econômico da doença, nas criações

${ }^{1}$ Médico Veterinário, Mestre em Ciências, Centro de Biotecnologia e Faculdade de Veterinária da Universidade Federal de Pelotas ${ }^{2}$ Médico Veterinário, Doutor em Ciências, Centro de Biotecnologia e Faculdade de Veterinária da Universidade Federal de Pelotas, CP 354, 96010-900, Pelotas-RS, Brasil. E-mail: gil@ufpel.tche.br. Autor para correspondência. 
bovinas dos países participantes do MERCOSUL, levou a considerá-la, em 1996, uma das oito doenças priorizadas para estudos através do PROCISUR (Programa de Desenvolvimento Científico do MERCOSUL patrocinado pelo BID).

A CIB foi diagnosticada na maioria dos estados brasileiros, no Uruguai, Argentina, Paraguai e Chile, onde afeta principalmente animais de raças européias. BAPTISTA \& RIBEIRO (1974) constataram que as regiões sul e de fronteira do Rio Grande do Sul são as mais atingidas pela doença. A CIB ocorre principalmente nas estações quentes, quando a população de vetores (Musca autumnalis e $\boldsymbol{M}$. domestica) e o foto-período aumentam. É uma doença altamente contagiosa, transmitida por contato direto, descarga nasal ou ocular e, principalmente por vetores mecânicos. A M. bovis pode sobreviver por mais de três dias nas patas das moscas (GERHARDT et al., 1982) e pode ser isolada tanto de animais sadios, que não padeceram a doença, quanto de animais recuperados. A CIB afeta animais de todas as idades, independentemente do sexo e raça, mas, em estabelecimentos onde é endêmica, as taxas de incidência são maiores nos animais jovens. Zebuínos e suas cruzas são menos freqüentemente afetados (WEBBER \& SELBY, 1981). Não há dados experimentais que demonstrem a transmissão interespecífica espontânea, apesar de o agente etiológico ter sido isolado de ovinos e eqüinos com conjuntivite (HUNTINGTON et al., 1987).

Os fatores primários de patogenicidade da M. bovis são as fímbrias (pili de aderência), proteínas de superfície, cuja função é a fixação da bactéria a receptores específicos das células epiteliais da córnea e conjuntiva (CHANDLER et al., 1979, GIL TURNES, 1983). Estas fímbrias são essenciais para a colonização do hospedeiro e também importantes imunógenos (LEHR et al., 1985, MOORE \& RUTTER, 1987, MATTICK et al., 1996).

Transcorrido mais de um século do primeiro relato desta enfermidade (Billings, apud BROWN et al., 1998), as medidas preventivas e terapêuticas disponíveis ainda têm limitado sucesso.

A forma mais eficiente de controlar a CIB é através da utilização de vacinas que contenham antígenos de fímbria. Em 1982, foi desenvolvida uma vacina com estes antígenos (GIL TURNES et al., 1982), que apresentou um índice de proteção de $83 \%$ ao desafio experimental. Essa vacina tem sido utilizada no Brasil, Uruguai e Argentina desde meados da década de 80 . Pesquisas realizadas, em diversas partes do mundo, revelaram a existência de diferentes sorotipos de fímbrias de M. bovis (GIL TURNES et al.,
1986, LEPPER \& HERMANS, 1986, MOORE \& RUTTER, 1987). GIL TURNES \& ALEIXO (1991) quantificaram adesinas de diferentes cepas mediante a utilização de anticorpos monoclonais e sugeriram a necessidade de monitorar as características antigênicas das cepas prevalentes na região visando à produção de vacinas eficientes.

A utilização nas vacinas de cepas não mais prevalentes na região, ou de outras regiões, a diversidade antigênica do agente etiológico e a ausência de estudos epidemiológicos poderiam explicar as freqüentes falhas das vacinas.

\section{ETIOPATOGENIA}

A M. bovis pertence à família Moraxellaceae. Com base em estudos de hibridização de DNA e análise da seqüência do rDNA, os gêneros Moraxella, Acinetobacter e Psychrobacter foram removidos da família Neisseriaceae e incluídos na família Moraxellaceae (ROSSAU et al., 1991). O gênero Moraxella, ainda bastante discutido, está constituído por 14 espécies (KODJO et al., 1997).

A M. bovis é uma bactéria Gram negativa, imóvel, aeróbica, oxidase positiva, variável para catalase e colagenase, que não esporula, não fermenta carboidratos nem reduz nitratos. O pleomorfismo é característico da espécie, apresentando-se aos pares ou em cadeias curtas, variando de cocos, a cocobacilos e bacilos (PUGH \& HUGHES, 1966). Em agar sangue, formam colônias lisas ou rugosas, com 1 a $3 \mathrm{~mm}$ de diâmetro, circulares, levemente esbranquiçadas e com um estreito halo de $\beta$ hemólise. Bactérias isoladas de casos clínicos de CIB formam colônias rugosas que se tingem pelo cristal violeta, auto-aglutinam em água destilada e aglutinam hemácias de varias espécies, características associadas à presença de fímbrias (BROWN et al., 1998). As colônias rugosas (fimbriadas), ao serem removidas do agar, deixam pequenas concavidades no meio de cultivo, fenômeno conhecido por corrosão do agar. Além disso, essas colônias também apresentam uma forma de translocação superficial conhecida como "twitching motility". Agar corrosão e "twitching motility" são características comuns a bactérias que expressam fímbrias tipo 4 (MATTICK et al., 1996).

As fímbrias tipo 4, também denominadas MePhe, são filamentos localizados nos pólos da bactéria constituídos por aproximadamente 10.000 monômeros protéicos com 15 a $20 \mathrm{kDa}$ de massa molecular (RUFFOLO et al., 1997) denominados pilina (MARRS \& WEIR, 1990). As fímbrias medem de 1 a $4 \mu \mathrm{m}$ de comprimento e $5,2 \mathrm{~nm}$ de diâmetro, podendo 
estar alongadas ou retraídas devido ao encaixe e desencaixe de pilina na base da fímbria (KEIZER et al., 2001), o que produz a "twitching motility". Cada pilina contém de 145 a 160 aminoácidos, dependendo da espécie (MATTICK et al., 1996), e uma região hidrofóbica altamente conservada na porção amino terminal, que é compartilhada por vários patógenos, tais como Moraxella bovis, $M$. nonliquefaciens, $M$. lacunata, Neisseria gonorrhoeae, $N$. meningitidis, Dichelobacter nodosus, Pseudomonas aeruginosa, Vibrio cholerae, Actinobacillus pleuropneumoniae e Pasteurella multocida. Outra característica das fímbrias tipo 4 é a presença do aminoácido modificado $\mathrm{N}$-metilfenilalanina (MePhe) como primeiro resíduo da proteína madura (MATTICK et al., 1996, ZHANG et al., 2000). Variações estruturais e antigênicas dentro e entre espécies ocorrem nos dois terços da região Cterminal da subunidade fimbrial (MATTICK et al., 1996). Estas fímbrias estão codificadas no cromossomo bacteriano, estimando-se que pelo menos 22 genes estão envolvidos na biossíntese e regulação das fímbrias tipo 4 de Pseudomonas aeruginosa (MATTICK et al., 1996). Fímbrias tipo 4 estão, freqüentemente, mas não obrigatoriamente, ligadas à competência para aquisição de DNA (transformação) e absorção de bacteriófagos (KEIZER et al., 2001).

Estas proteínas constituem os fatores primários de patogenicidade, já que são responsáveis pela aderência às células epiteliais do hospedeiro. Tem sido demonstrado que cepas de $\boldsymbol{M}$. bovis, cujas fímbrias foram desnaturadas por tratamento químico $\left(\mathrm{MgCl}_{2}\right.$ a $\left.10 \%\right)$, perderam sua patogenicidade para bovinos, a auto-aglutinabilidade e a propriedade de aglutinar hemácias (GIL TURNES, 1983). ANNUAR \& WILCOX (1985) sugeriram que a adesão de cepas fimbriadas, em cultura de células, foi mediada pelas fímbrias, porém outras adesinas podem estar envolvidas na adesão de cepas não fimbriadas de $\boldsymbol{M}$. bovis.

Além da expressão de fímbrias, cepas patogênicas de $\boldsymbol{M}$. bovis sintetizam uma $\beta$ hemolisina (BILLSON et al., 2000), que tem uma importante função na patogênese. Cepas não hemolíticas são freqüentemente isoladas de bovinos e não estão associadas, geralmente, com doença clínica (BROWN et al., 1998). Estudos recentes indicam que a $\beta$ hemolisina de $\boldsymbol{M}$. bovis pertence à família RTX de exoproteínas bacterianas (BILLSON et al., 2000, ANGELOS et al., 2001), caracterizada por produzir poros na membrana citoplasmática das células alvo (epiteliais, leucócitos, hemácias), provocando efluxo de potássio, desequilíbrio osmótico e lise (ANGELOS et al., 2001). Esta exotoxina depende de cálcio para lesar hemácias, células epiteliais da córnea e leucócitos (BEARD \& MOORE, 1994) e provavelmente está codificada em um operon composto por 4 genes denominados A, B, $\mathrm{C}$ e D. A toxina (produto do gene A) é ativada pelo produto do gene $\mathrm{C}$ e transportada por proteínas de membrana codificadas pelos genes B e D (ANGELOS et al., 2001). Macrófagos e neutrófilos lisados pela LKT, uma toxina da família RTX produzida pela Manhemia (Pasteurella) haemolytica, liberam enzimas e reativos intermediários de oxigênio, que destroem tecidos adjacentes (CULLOR \& SMITH, 1996).

Além destes dois importantes fatores de patogenicidade (fímbrias e $\beta$ hemolisina), a M. bovis, assim como outras bactérias Gram negativas, possui lipopolissacarídeo somático (LPS ou endotoxina). Segundo ABBAS et al. (1994) e CULLOR \& SMITH (1996), o LPS estimula macrófagos, células endoteliais e linfócitos, que, por sua vez, liberam uma série de citocinas (TNF, IL-1, IL-6). Essas citocinas induzem a adesão de neutrófilos e monócitos ao endotélio vascular, ativam e atraem células inflamatórias (quimiotaxia) e são mediadores do choque endotoxínico. A liberação de endotoxinas também induz outros eventos, como a ativação da via alternativa do sistema complemento e da cascata de coagulação, e o recrutamento de neutrófilos e macrófagos ativados (CULLOR \& SMITH, 1996), aumentando o processo inflamatório no foco infeccioso. O marcado influxo de neutrófilos, no foco infeccioso, é uma importante causa de injúria tecidual, uma vez que tecidos adjacentes normais também são destruídos pela resposta inflamatória (ABBAS et al., 1994). O LPS de M. bovis é pirogênico e induz reação de Shwartzman em coelhos (ARAÚJO, 1986), estimula a liberação de interleucina 1 e fator de necrose tumoral, e induz a blastogênese de linfócitos B (JOHANSEN et al., 1990).

Após a adesão à camada externa da córnea, M. bovis invade o estroma, modifica a disposição das fibras de colágeno, necrosa as células e produz uma úlcera (CHANDLER et al., 1983, ROGERS et al., 1987). FRANCO \& GIL TURNES (1994) detectaram colagenase e DNAse em culturas totais, e dermonecrotoxinas e citotoxinas para células BHK 21 nos filtrados de doze cepas de $\boldsymbol{M}$. bovis isoladas no Brasil e Uruguai. Uma enzima secretada por $\boldsymbol{M}$. bovis com atividade de fosfolipase B, foi recentemente caracterizada por FARN et al. (2001). Fosfolipases, enzimas reconhecidas como o principal fator de virulência de alguns patógenos bacterianos, incluindo Listeria (GOLDFINE et al., 1995) e Corynebacterium pseudotuberculosis (McNAMARA et al., 1994), atuam hidrolisando os fosfolipídios de membranas biológicas, provocando lise celular e auxiliando na resistência à fagocitose. 
MARRION \& RILEY (2000) detectaram um fator solúvel produzido por $\boldsymbol{M}$. bovis, que provoca a separação de células de diferentes linhagens in vitro, incluindo células epiteliais da córnea. Esta exfoliatina pode participar na patogênese, facilitando a invasão da córnea.

Estudos in vitro sugerem que a $M$. bovis possui um eficiente sistema de aquisição de ferro constituído por sideróforos e receptores de membrana externa, que reconhecem lactoferrina e transferrina bovinas (FENWICK et al., 1996, BROWN et al., 1998), duas proteínas capazes de quelar ferro presente nas secreções mucosas e no soro sanguíneo, respectivamente (BROWN et al., 1998). A capacidade de $\boldsymbol{M}$. bovis multiplicar-se em meios com baixo conteúdo de ferro e de utilizar lactoferrina e transferrina bovina como fontes de ferro, sugere um importante mecanismo de virulência.

\section{DIVERSIDADE ANTIGÊNICA}

As diferenças na proteção induzida por vacinas frente a desafios com cepas homólogas e heterólogas permitiram a formulação da hipótese que existiam cepas de $\boldsymbol{M}$. bovis antigenicamente distintas (PUGH \& HUGHES, 1976, PUGH et al., 1978, LEHR et al., 1985, BROWN et al., 1998).

GIL TURNES \& ARAÚJO (1982) identificaram seis sorogrupos de antígenos somáticos de M. bovis através de um teste de imunodifusão, entre isolados recuperados na Argentina, Brasil, Uruguai e Estados Unidos da América. LEPPER \& HERMANS (1986) detectaram seis grupos antigenicamente distintos de fímbrias na Austrália através de um ELISA, e MOORE \& RUTTER (1987) sete grupos fimbriais no Reino Unido através de soroaglutinação. MOORE \& RUTTER (1987), VANDERGAAST \& ROSENBUSCH (1989) e GIL TURNES \& ALEIXO (1991) encontraram reatividade cruzada entre cepas pertencentes a diferentes sorotipos fimbriais. Entretanto, MOORE \& LEPPER (1991) propuseram um sistema de caracterização unificado, baseado nas propriedades antigênicas das fimbrias, identificando sete sorogrupos (denominados de A a G) entre isolados recuperados na Grã-Bretanha, Austrália, Nova Zelândia e EUA. Recentemente, PRIETO et al. (1999) identificaram três perfis de proteínas de membrana externa (OMPs, outer membrane proteins) e três tipos de LPS em isolados argentinos recuperados em surtos de CIB.

GREENE et al. (2001) encontraram determinantes antigênicos ocultos em fimbrias de $\boldsymbol{M}$. bovis pertencentes a diferentes sorotipos, que não são imunogênicos na fímbria intacta, mas que se tornam imunogênicos após a clivagem da fímbria com brometo de cianogênio. Anti-soros produzidos com as fimbrias fragmentadas reagiram com fimbrias intactas de cepas heterólogas, sugerindo que vacinas produzidas com fímbrias tratadas com brometo de cianogênio poderiam induzir proteção cruzada.

CONCEIÇÃO (2002) determinou o índice de reatividade cruzada (IRC) de vinte e oito isolados de M. bovis recuperados em surtos de CIB ocorridos entre 1983 e 2000 na Argentina, Rio Grande do Sul (Brasil) e Uruguai, através de um ELISA indireto. Os isolados foram distribuídos em sete sorogrupos, colocando no mesmo sorogrupo cepas que apresentaram IRC $\geq 70$ (Tabela 1). Neste estudo, ficou comprovado que o perfil antigênico dos isolados prevalentes de $\boldsymbol{M}$. bovis alterou-se ao longo das duas últimas décadas e que a utilização extensiva de vacinas na Argentina e Uruguai pode ter provocado esta alteração.

Além da diversidade de antígenos somáticos e fimbriais, M. bovis pode sofrer variação de fase. Variação de fase é um processo pelo qual as bactérias alteram a expressão de antígenos de superfície de forma reversível, possibilitando a colonização e sua sobrevivência na presença de anticorpos específicos (GILSDORF, 1998). A M. bovis pode ter mais de um gene codificador de pilina que codificam pilinas diferentes, $\alpha$ e $\beta$, situados em uma região inversora de 2.1 kilobases localizada no DNA genômico da bactéria (MARRS et al., 1988), sendo transcrito o gene que estiver adjacente ao promotor. LEPPER et al. (1995) sugeriram que a inversão gênica pode ser induzida por anticorpos presentes nas lágrimas e nos tecidos oculares. HOBBS et al. (1991) comprovaram que a transferência lateral de genes que codificam pilinas pode ocorrer naturalmente entre espécies que expressam fímbria tipo 4.

O estudo da diversidade antigênica das cepas de M. bovis é um pré-requisito para o sucesso de um programa imunoprofilático, uma vez que os sorogrupos prevalentes variam durante o transcurso de um surto (GIL TURNES \& ALBUQUERQUE, 1984, CONCEIÇÃO, 2002) e entre regiões (GIL TURNES \& ARAÚJO, 1982, LEPPER \& HERMANS, 1986), exigindo a caracterização antigênica periódica das cepas prevalentes na região visando à produção de vacinas eficientes.

\section{DIVERSIDADE GENÉTICA}

A comprovação da ampla diversidade antigênica de M. bovis, como demonstrado acima, indica que a espécie deve apresentar uma correspondente diversidade genética. 
Tabela 1 - Índice de reatividade cruzada e sorogrupos de 28 cepas de M. bovis recuperadas na Argentina, Brasil e Uruguai entre 1983 e 2000.

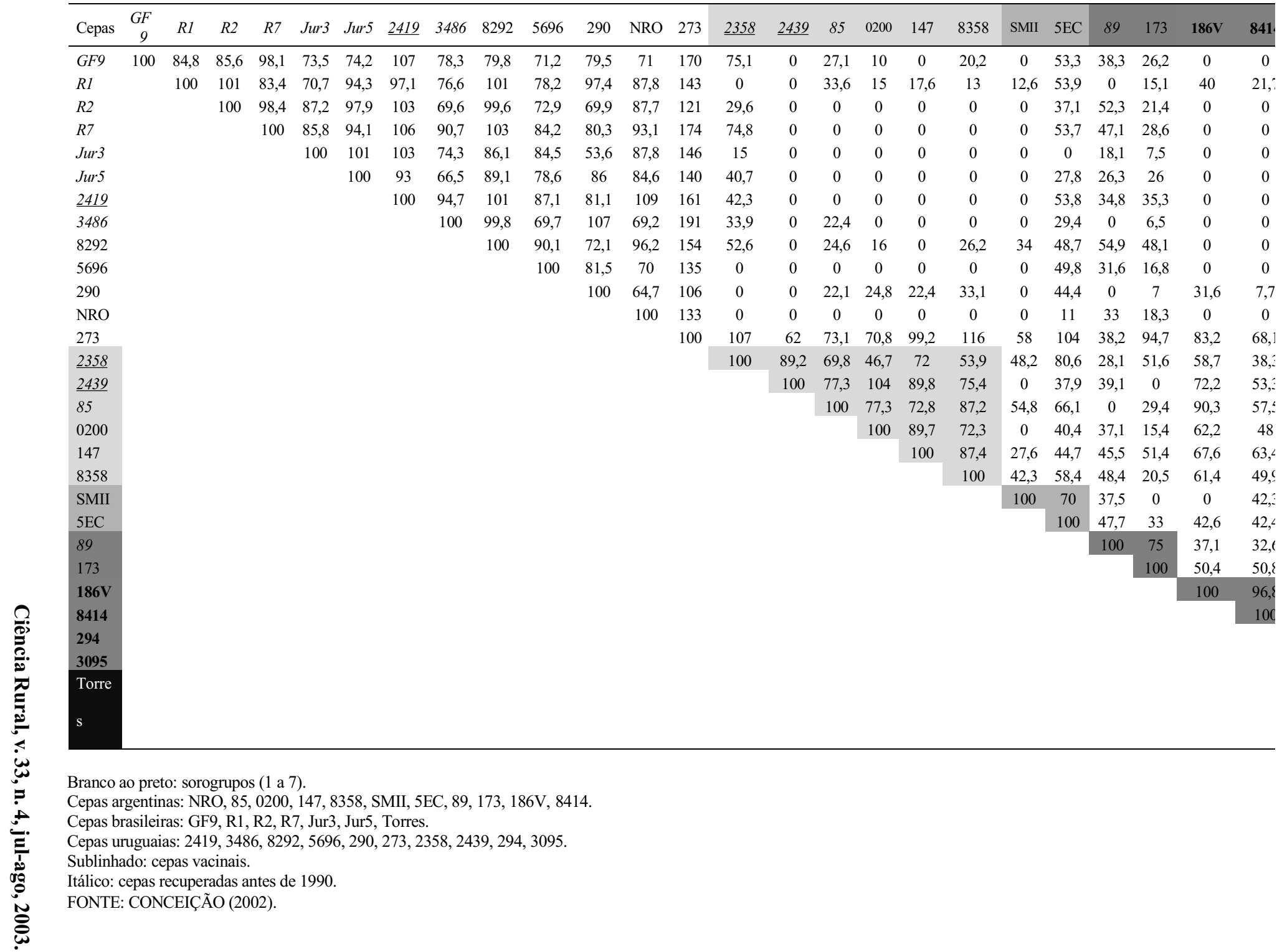




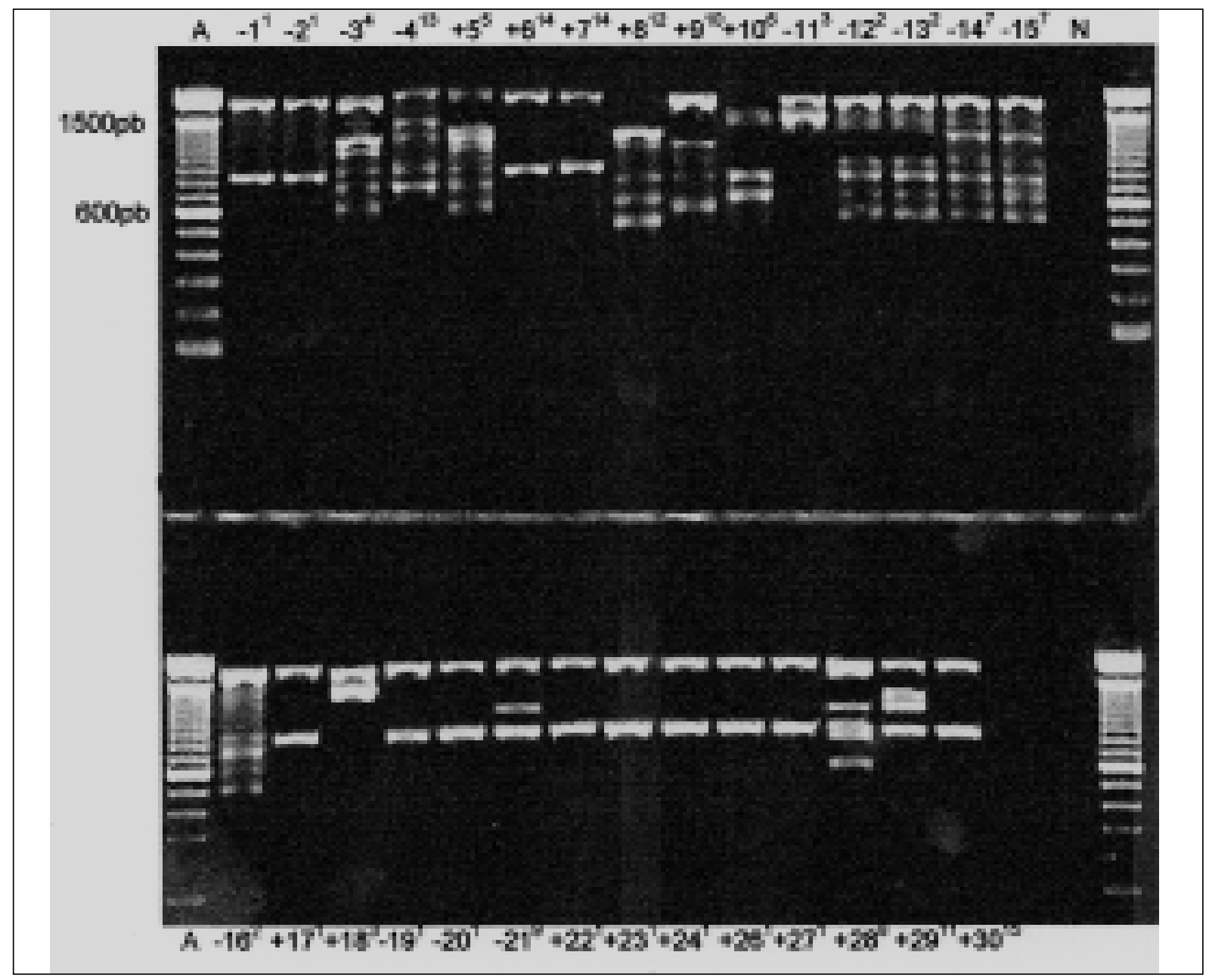

Figura 1 - Eletroforese em gel de agarose a 1,2\% de um RAPD com o primer 103 (GTG ACG CCG C) Um a 10, isolados uruguaios, 11 a 18, isolados brasileiros, 19 a 30, isolados argentinos (Tabela 1). A, ladder 100pb. N, controle negativo. Os sinais de negativo e positivo correspondem às datas de isolamento, antes e após 1990, respectivamente. Sobrescrito, perfil de RAPD.

Perfis plasmidiais diferentes, em cepas patogênicas e não patogênicas da bactéria, constituídos por três e cinco plasmídios, respectivamente, foram encontrados por SCHURIG et al. (1984), o que sugere que alguns fatores de patogenicidade pudem estar codificados neles. GIL TURNES et al. (1989) encontraram diferentes perfis plasmidiais entre quatorze cepas isoladas no Rio Grande do Sul, não relacionados com a síntese de fatores de patogenicidade. WILT et al. (1990) tampouco encontraram relação entre perfil plasmidial e presença de fímbrias.

A comunicação por MARRS et al. (1985), de que os genes responsáveis pela síntese das pilinas estão situados no cromossomo, direcionaram o estudo da variação genética de $\boldsymbol{M}$. bovis para estas estruturas. PRIETO et al. (1999) estudaram a diversidade genética de cinqüenta e cinco isolados argentinos de $\boldsymbol{M}$. bovis através de primers para ERIC (enterobacterial repetitive intergeneric consensus) e observaram que a população estudada, formada por cinco grupos genéticos, era relativamente homogênea.

Recentemente, CONCEIÇÃO (2002) encontrou quinze perfis moleculares, detectados através de Random Amplified Polymorphic DNA (RAPD-PCR), entre trinta isolados de $\boldsymbol{M}$. bovis recuperados em surtos de CIB ocorridos entre $1974 \mathrm{e}$ 2001 na Argentina, Brasil-RS e Uruguai (Figura 1). Metade deles pertencia ao sorogrupo I, o mais prevalente, produzindo uma banda de 800 pares de bases com o primer 119 (ATTGGGCGAT) e sugerindo uma relação genótipo-fenótipo. Além disso, $48 \%$ dos isolados apresentaram perfis diferentes dos de cepas vacinais utilizadas na região desde há mais de 15 anos, 
sugerindo que houve uma pressão de seleção pelas vacinas ao longo do período estudado.

\section{SUSCEPTIBILIDADE AOS ANTIBIÓTICOS}

Antimicrobianos são utilizados no mundo todo para o tratamento de casos clínicos de CIB. Constatou-se que existem diferenças nos padrões de susceptibilidade entre cepas isoladas em locais distintos, de um mesmo rebanho ao longo de um surto (GIL TURNES \& ALBUQUERQUE, 1984) ou de um mesmo animal (SCHRAMM \& ARAÚJO, 1994), indicando a necessidade de determinar a sensibilidade in vitro antes de iniciar o tratamento (SMITH \& GEORGE, 1985, BROWN et al., 1998).

A $\boldsymbol{M}$. bovis é freqüentemente susceptível à gentamicina, cefalosporinas de primeira geração, trimetroprima-sulfonamidas, nitrofuranos e tetraciclinas (BROWN et al., 1998), aplicados topicamente em suspensão, pomadas ou aerossóis. A administração parenteral de formulações LA (longa ação) mantém concentrações nas lágrimas próximas à concentração inibitória mínima (MIC) por 24 horas (PUNCH et al., 1985). Altas concentrações de antibiótico também podem ser atingidas no filme lacrimal por injeção subconjuntival, embora essa forma de administração possa causar reações locais indesejáveis. A administração de preparados LA pode provocar necrose, e, por isso, não é recomendada por esta via (BROWN et al., 1998).

SHRYOCK et al. (1998) detectaram entre 55 isolados de $\boldsymbol{M}$. bovis recuperados nos EUA de 1980 a $1990,26 \%$ de cepas resistentes à oxitetraciclina e 16,5 $\%$ à gentamicina. Esses autores também comprovaram que $31 \%$ deles eram suscetíveis à eritromicina. CONCEIÇÃO (2002) determinou a susceptibilidade antimicrobiana de 30 isolados de $\boldsymbol{M}$. bovis recuperados entre 1974 e 2001 na Argentina, Brasil-RS e Uruguai, através das técnicas de Kirby-Bauer (BARRY \& THORNSBERRY, 1980) e MIC por diluição em agar (WASHINGTON \& SUTTER, 1980). Todas as amostras foram sensíveis a ampicilina, cefalosporina, estreptomicina, gentamicina, neomicina, nitrofurantoína, rifampicina e tetraciclina, e 57 e $77 \%$ resistentes à lincomicina e novobiocina, respectivamente, pelo método de Kirby-Bauer. As $\operatorname{MICs}(\mu \mathrm{g} / \mathrm{ml})$ foram: Ampicilina $\leq 0,75$, gentamicina $\leq$ 0,25 , cefalosporina $\leq 1,5$ e rifampicina $\leq 1,5$. Com os outros antibióticos, houve uma variação entre $\leq 0,25$ e 2,0 , para neomicina e tetraciclina, $\leq 8$ e 32 para nitrofurantoína, $\leq 0,75$ e 6 , para estreptomicina, $\leq 0,05$ e 1 , para eritromicina, e $\leq 1$ e 4 para kanamicina. Amostras brasileiras apresentaram MIC média superior $(\mathrm{p}<0,05)$ a das uruguaias e argentinas para estreptomicina, neomicina, kanamicina e nitrofurantoína. Também ficou comprovado que houve uma redução na susceptibilidade à eritromicina ao longo das duas últimas décadas.

A eficácia da antibioticoterapia depende das propriedades farmacológicas da droga. Quanto maior seja sua lipossolubilidade, melhor será a distribuição pelos tecidos e fluídos corporais (PUNCH et al., 1985). Rifampicina, eritromicina e tetraciclina, particularmente, apresentam esta característica (MERCK, 1996). No entanto, na maioria das vezes, as propriedades farmacocinéticas das drogas selecionadas não são levadas em consideração na escolha do tratamento.

\section{CONCLUSÕES}

A CIB continua sendo uma doença economicamente importante na maioria dos países criadores de bovinos. Embora, nas duas últimas décadas, tenha havido progressos relevantes no conhecimento básico da $\boldsymbol{M}$. bovis, é essencial manter ações de vigilância epidemiológica visando a monitorar o perfil antigênico das cepas prevalentes regionalmente como forma de conseguir vacinas eficientes, assim como determinar o perfil de susceptibilidade aos antibióticos antes de instaurar o tratamento.

\section{REFERÊNCIAS BIBLIOGRÁFICAS}

ABBAS, K.A.; LICHTMAN, H.A.; POBER, S.J. Cellular and Molecular Immunology. 2.ed. Philadelphia, Pennsylvania : Saunders, 1994. p.320.

ANGELOS, J.A.; HESS, J.F.; GEORGE, L.W. Cloning and characterization of a Moraxella bovis cytotoxin gene. American Journal of Veterinary Research, v.62, n.8, p.1222-1228, 2001.

ANNUAR, B.O.; WILCOX, G.E. Adherence of Moraxella bovis to cell cultures of bovine origin. Research in Veterinary Science, v.39, p.241-246, 1985.

ARAÚJO, F.L. Estudo de estruturas de superfície da espécie Moraxella bovis. 1986. 95f. Tese (Doutorado em Microbiologia) - Instituto de Microbiologia da Universidade Federal do Rio de Janeiro, 1986.

BAPTISTA, P.J.H.P. Infectious bovine keratoconjunctivitis: a review. British Veterinary Journal, v.135, p.225-242, 1979.

BAPTISTA, P.J.H.P.; RIBEIRO, L.A.O. Querato-conjuntivite infecciosa dos bovinos no Rio Grande do Sul. Atualidades Veterinárias, v.3, p.10-15, 1974.

BARRY, A.L.; THORNSBERRY, C. Susceptibility testing: Diffusion test procedures. In: LENNETTE, E.H. Manual of 
Clinical microbiology. 3.ed. Washington DC. : American Society For Microbiology, 1980. p.464.

BEARD, M.K.; MOORE, L.J. Reproduction of bovine Keratoconjunctivitis with a purified haemolytic and cytotoxic fraction of Moraxella bovis. Veterinary Microbiology, v.42, p.15-33, 1994.

BILLSON, F.M. et al. Characterization of hemolysin of Moraxella bovis using a hemolysis-neutralizing monoclonal antibody. Infection and Immunity, v.68, n.6, p.3469-3474, 2000.

BROWN, M.H. et al. Infectious bovine keratoconjunctivitis: A Review. Journal of Veterinary Internal Medicine, v.12, p.259-266, 1998.

CHANDLER, R.L.; BAPTISTA, P.J.H.P.; TURFREY, B. Studies on the pathogenicity of Moraxella bovis in relation to infectious bovine keratoconjunctivitis. Journal of Comparative Pathology, v.89, p.441-448, 1979.

CHANDLER, R.L.; TURFREY, B.A.; SMITH, K. Laboratory model for Infectious Bovine Keratoconjunctivitis: the pathogenicity of different strains of Moraxella bovis, pathology and ultrastructural observations. Research in Veterinary Science, v.35, p.277-284, 1983.

CONCEIÇÃO, F.R. Caracterização antigênica e molecular de isolados de Moraxella bovis recuperados em surtos de Ceratoconjuntivite Infecciosa Bovina ocorridos entre 1974 e 2001 na Argentina, Brasil e Uruguai. 2002. 196f. Dissertação (Mestrado em Medicina Veterinária) - Curso de Pós-graduação em Medicina Veterinária, Universidade Federal de Pelotas.

CULLOR, S.J.; SMITH, W.L. Endotoxin and disease in food animals. Compendium Continuing Education Veterinarian Practioner, v.18, n.1, p.31-37, 1996.

FARN, J.L. et al. Molecular characterization of a secreted enzyme with phospholipase B activity from Moraxella bovis. Journal of Bacteriology, v.183, n.22, p.6717-6720, 2001.

FENWICK, B. et al. Iron repressible outer membrane proteins of Moraxella bovis and demonstration of siderophore-like activity. Veterinary Microbiology, v.48, p.315-324, 1996.

FRANCO, M.A.; GIL TURNES, C. Toxins of Moraxella bovis: Effect on substrates and cells. Revista de Microbiologia, v.25, n.4, p.235-238, 1994.

GERHARDT, R.R. et al. The role of face flies in an episode of Infectious Bovine Keratoconjunctivitis. Journal of the American Veterinary Medical Association, v.180, p.156$159,1982$.

GILSDORF, J.R. Antigenic diversity and gene polymorphisms in Haemophilus influenzae. Infection and Immunity, v.66, n.11, p.5053-5059, 1998.

GIL TURNES, C. Hemagglutination, autoagglutination and pathogenicity of Moraxella bovis strains. Canadian Journal of Comparative Medicine, v.47, p.503-504, 1983.

GIL TURNES, C. Ceratoconjuntivite infecciosa bovina. In: RIET-CORREA, F.; SCHILD, A.L.; MÉNDEZ, M.C. Doenças de ruminantes e eqüinos. Pelotas : Universitária/UFPel, 1998. p.180-191.
GIL TURNES, C.; ARAÚJO, F.L. Serological characterization of strains of Moraxella bovis using double immunodiffusion. Canadian Journal of Comparative Medicine, v.46, p.165-168, 1982.

GIL TURNES, C.; ALBUQUERQUE, I.M.B. Serotypes and antibiotic sensitivity of Moraxella bovis isolated from an outbreak of infectious bovine keratoconjunctivitis. Canadian Journal of Comparative Medicine, v.46, p.428-430, 1984.

GIL TURNES, C.; ALEIXO, J.A.G. Quantification of Moraxella bovis haemagglutinating adhesins with monoclonal antibodies. Letters in Applied Microbiology, v.13, p.55-57, 1991.

GIL TURNES, C. et al. Comparação da proteção induzida por vacinas de Moraxella bovis com e sem antígenos de pili. In: CONGRESSO BRASILEIRO DE MEDICINA VETERINÁRIA, 18., 1982, Camboriú-SC, Brasil. Anais... Camboriú : n.i, 1982. p.11.

GIL TURNES, C. et al. Serological characterization of adhesins of Moraxella bovis. In: INTERNATIONAL CONGRESS OF MiCROBIOLOGY, 14., 1986, Manchester. Proceedings... Manchester : International Union of Microbiological Societies, 1986. p. 281 .

GIL TURNES, C. et al. Perfil de plasmídeos e síntese de fatores de patogenicidade de Moraxella bovis. In: Congresso Brasileiro de Microbiologia, 15., 1989, Ribeirão Preto, SP. Anais... Ribeirão Preto: Sociedade Brasileira de Microbiologia, 1989 . p.104.

GOLDFINE, H. et al. Membrane permeabilization by Listeria monocytogenes phosphatidylinositol-specific phospholipase $\mathrm{C}$ is independent of phospholipid hydrolysis and cooperative with listeriolysin. Proceedings of the National Academy of Sciences, v.92, p.2979-2983, 1995.

GREENE, W.H.; GRUBBS, S.T.; POTGIETER, L.N.D. Immunoblot analysis of cyanogen bromide-cleaved Moraxella bovis pilin reveals presence of shared antigenic determinants on pili from heterologous strains. Veterinary Microbiology, v.80, p.365-372, 2001.

HOBBS, M. et al. Organization of the fimbrial gene region of Bacteroides nodosus: class I and class II strains. Molecular Microbiology, v.5, p.543-560, 1991.

HUNTINGTON, P.J. et al. Isolation of Moraxella sp. from horses with conjunctivitis. Australian Veterinary Journal, v.64, p.118119, 1987.

JOHANSEN, K.A.; WANNEMUEHLER, M.J.; ROSENBUSCH, R.F. Biological reactivity of Moraxella bovis lipopolysaccharide. American Journal of Veterinary Research, v.51, n.1, p.46-51, 1990 .

KEIZER, D.W. et al. Structure of a pilin monomer from Pseudomonas aeruginosa. Journal of Biological Chemistry, v.276, n.26, p.24186-24193, 2001.

KIRKPATRICK, J.G.; LALMAR, D. Pinkeye in cattle infectious bovine keratoconjunctivitis (IBK). 1997. On line. Disponível em: http: // vetgate.ac.uk . Acessado em 11/04/2001. 
KODJO, A.; EXBRAYAT, P.; RICHARD, Y. Identification of Moraxella bovis and related species from calves with IBK and goats by qualitative genetic transformation assay. Journal of Veterinary Medicine, v.41, p.336-343, 1994.

KODJO, A.; RICHARD, Y.; TONJUM, T. Moraxella boevrei sp. nov., a new Moraxella species found in goats. International Journal of Systematic Bacteriology, v.47, n.1, p.115-121, 1997.

LEHR, C.; JAYAPPA, H.G.; GOODNOW, R.A. Serologic and protective characterization of Moraxella bovis pili. Cornell Veterinary, v.75, p.484-492, 1985

LEPPER, A.W.D.; HERMANS, L.R. Characterization and quantitation of pilus antigens of Moraxella bovis by ELISA. Australian Veterinary Journal, v.63, p.401405, 1986

LEPPER, A.W.D. et al. The protective efficacy of pili from different strains of Moraxella bovis within the same serogroup against Infectious Bovine Keratoconjunctivitis. Veterinary Microbiology, v.32, n.2, p.177-187, 1992.

LEPPER, A.W.D. et al. The protective efficacy of cloned Moraxella bovis pili in monovalent and multivalent vaccine formulations against experimentally induced infectious bovine keratoconjunctivitis (IBK). Veterinary Microbiology, v.45, p.129-138, 1995.

MARRION, R.M.; RILEY, L.K. Detection of cell detachment activity induced by Moraxella bovis. American Journal of Veterinary Research, v.9, p.1145-1149, 2000.

MARRS, C.F. et al. Cloning and sequencing of a Moraxella bovis pilin gene. Journal of Bacteriology, v. 163, p. 132139, 1985.

MARRS, C.F.; WEIR, S. Pili (fimbriae) of Branhamella species. American Journal of Medicine, v.88, p.36-40, 1990.

MARRS, C.F. et al. Pilin gene phase variation of Moraxella bovis is caused by an inversion of pilin genes. Journal of Bacteriology, v.170, p.3032-3039, 1988 .

MATTICK, J.S.; WHITCHURCH, C.B.; ALM, R.A. The molecular genetics of type 4 fimbriae in Pseudomonas aeruginosa - a review. Gene, v.179, p.147-155, 1996.

McNAMARA, P. J.; BRADLEY, G.A.; SONGER, J.G. Targeted mutagenesis of the phospholipase $\mathrm{D}$ gene results in decreased virulence of Corynebacterium pseudotuberculosis. Molecular Microbiology, v.12, p.921-930, 1994.

MERCK. Manual Merck de Veterinária. Um manual de diagnóstico, tratamento, prevenção e controle de doenças para o veterinário. 7.ed. São Paulo : Roca, 1996. p.942.

MOORE, L.S.; RUTTER, J.M. Antigenic analysis of fimbrial proteins from Moraxella bovis. Journal of Clinical Microbiology, v.25, p.2063-2070, 1987.

MOORE, L.S.; LEPPER, A.W.D. A unified serotyping scheme for Moraxella bovis. Veterinary Microbiology, v.29, p.75$83,1991$.
PRIETO, C.I.; AGUILAR, M.O.; YANTORNO, O.M. Analyses of lipopolysaccharides, outer membrane proteins and DNA fingerprints reveal intraspecies diversity in Moraxella bovis isolated in Argentina. Veterinary Microbiology, v.70, p.213223, 1999

PUGH, G.; HUGHES, D. The isolation and characterization of Moraxella bovis. American Journal of Veterinary Research, v.27, p.957-962, 1966.

PUGH, G.W.; HUGHES, D.E. Experimentally induced infectious bovine keratoconjunctivitis: resistance of vaccinated cattle to homologous and heterologous strains of Moraxella bovis. American Journal of Veterinary Research, v.37, n.1, p.5760, 1976.

PUGH, G.W.; HUGHES, D.E.; BOOTH, G.D. Serologic response of vaccinated cattle to strains of Moraxella bovis isolated during epizooties of keratoconjunctivitis. American Journal of Veterinary Research, v.39, n.1, p.55-57, 1978.

PUNCH, P.; GERHARDT, R.; ALLEN, J. The role of face flies in a episode of infectious bovine keratoconjunctivitis. Journal American Veterinary Medical Association, v.180, p.156159,1982

PUNCH, P.I. et al. Plasma and tear concentrations of antibiotics administered parenterally to cattle. Research in Veterinary Science, v.39, p.179-187, 1985.

ROGERS, D.G.; CHEVILLE, N.F.; PUGH, G.W. Pathogenesis of corneal lesions caused by Moraxella bovis in gnotobiotic calves. Veterinary Pathology, v.24, p.287-295, 1987.

ROSSAU, R. et al. Taxonomy of Moraxellaceae fam. Nov., a new bacterial family to accommodate the genere Moraxella, Acinetobacter and Psychrobacter and related organisms. International Journal of Systematic Bacteriology, v.41, p.310-319, 1991.

RUFFOLO, C.G. et al. Identification, purification, and characterization of the type 4 fimbriae of Pasteurella multocida. Infection and Immunity, v.65, n.1, p.339-343, 1997.

SCHRAMM, R.C.; ARAÚJO, F.L. Diferenças antigênicas de clones de Moraxella bovis. Pesquisa Veterinária Brasileira, v.14, p.75-78, 1994

SCHURIG, G.G. et al. Genotypic, phenotypic, and biological characteristics of Moraxella bovis. American Journal of Veterinary Research, v.45, n.1, p.35-39, 1984.

SHRYOCK, T.R.; WHITE, D.W.; WERNER, C.S. Antimicrobial susceptibility of Moraxella bovis. Veterinary Microbiology, v.61, p.305-309, 1998.

SLATTER, D.H. et al. A national survey of the occurrence of infectious bovine keratoconjunctivitis. Australian Veterinary Journal, v.59, p.65-72, 1982.

SMITH, J.A.; GEORGE, L.W. Treatment of acute ocular Moraxella bovis infections in calves with a parenterally administered long-acting oxytetracycline formulation. American Journal of Veterinary Research, v.46, n.4, p.804-807, 1985 . 
TROUT, H.F.; SCHURIG, G.D. "Pinkeye". Animal Nutrition and Health, February, p.38-41, 1985.

VANDERGAAST, N.; ROSENBUSCH, R.F. Infectious bovine keratoconjunctivitis epizootic associated with area-wide emergence of a new Moraxella bovis pilus type. American Journal of Veterinary Research, v.50, n.9, p.1437-1441, 1989.

WASHINGTON, J.A.; SUTTER, V.L. Susceptibility test: Agar and macro-broth dilution procedures. In: LENNETTE, E.H. Manual of clinical microbiology. 3.ed. Washington DC. : American Society for Microbiology, 1980. p.453-458.
WEBBER, J.; SELBY, L. Risk factors related to the prevalence of infectious bovine keratoconjunctivitis. American Journal of Veterinary Research, v.179, p.823-826, 1981.

WILCOX, G.E. The etiology of infectious bovine keratoconjunctivitis in Queensland. 1. Moraxella bovis. Australian Veterinary Journal, v.46, p.409-414, 1970.

WILT, G.R. et al. Plasmid content of piliated and nonpiliated forms of Moraxella bovis. American Journal of Veterinary Research, v.51, p.171-173, 1990.

ZHANG, Y. et al. Identification of type 4 fimbriae in Actinobacillus pleuropneumoniae. FEMS Microbiology Letters, v.189, p.15-18, 2000. 